\title{
Mediastinal Lymph Node Sampling
}

National Cancer Institute

\section{Source}

National Cancer Institute. Mediastinal Lymph Node Sampling. NCI Thesaurus. Code C139751.

A surgical procedure in which a single or multiple mediastinal lymph nodes are removed for microscopic examination. 